\title{
Clinical Manifestations, Neuroimaging Findings, and Treatment of Idiopathic Intracranial Hypertension in a Nepalese Tertiary Centre
}

\author{
Niraj Gautam ${ }^{1}$, Rajeev Ojhal, Sanjeev Kharel', Bikram Prasad Gajurel ${ }^{1}$, Sanjeeta
} Sitaula ${ }^{3}$, Ragesh Karn ${ }^{1}$, Reema Rajbhandari ${ }^{l}$, Ashish Shrestha ${ }^{l}$

${ }^{1}$ Department of Neurology, Tribhuvan University Institute of Medicine, Kathmandu, Nepal

${ }^{2}$ Maharajgunj Medical Campus, Tribhuvan University Institute of Medicine, Kathmandu, Nepal

${ }^{3}$ Department of Ophthalmology, Tribhuvan University Institute of Medicine, Kathmandu, Nepal

\section{ABSTRACT}

Introduction: Idiopathic Intracranial Hypertension is characterized by headache, visual impairment, papilledema, and increased cerebrospinal fluid opening pressure. We aim to evaluate clinical manifestations, neuroimaging findings, and treatment of Idiopathic Intracranial Hypertension in a Nepalese tertiary center.

Materials and Methods: We retrospectively included patients with the diagnosis of Idiopathic Intracranial Hypertension who were admitted to the Neurology department of Tribhuvan University Teaching Hospital from 2019 June to 2021 May and presented to the Neuro-ophthalmology outpatient clinic of the hospital for follow-up.

Results: Out of 16 Idiopathic Intracranial Hypertension patients, 12(75\%) patients had either headache or ocular pain. Reduced visual acuity and progressive visual loss were found in $44 \%$ of patients. Normal CSF opening pressure was found in $19 \%, 44 \%$ had CSF opening pressure at a range of $20-30 \mathrm{~cm} \mathrm{H}_{2} 0$ and $>30 \mathrm{~cm} \mathrm{H}_{2} 0$ in $37.5 \%$. 15 Idiopathic Intracranial Hypertension patients $(93.7 \%)$ were subtyped as Typical and 1 patient was diagnosed as Fulminant Idiopathic Intracranial Hypertension. Acetazolamide was used for treatment in 15 patients and 1 patient needed ventriculoperitoneal shunting. Seven patients (44\%) had some abnormal findings: partial empty sella $(44 \%)$, and tortuous optic nerve (31\%), flattened posterior eyeball (31\%), and hypoplastic transverse sinus $(19 \%)$.

Conclusions: Idiopathic Intracranial Hypertension is an uncommon diagnosis but should be suspected in patients with chronic headaches with visual impairment. In low-resource settings, proper history along with neurological and ophthalmological examinations can even detect the early features and timely referral can save the vision and disability of Idiopathic Intracranial Hypertension patients.

Keywords: Acetazolamide; Chronic headache; Idiopathic intracranial hypertension; Visual loss
Correspondence:

Dr. Rajeev Ojha

Department of Neurology, Tribhuvan University

Institute of Medicine,

Maharajgunj, Kathmandu 44600, Nepal

ORCID ID: 0000-0001-7680-7036

Email: rajeevnet@hotmail.com

Submitted: $21^{\text {st }}$ November 2021 Accepted: $9^{\text {th }}$ December 2021

Source of Support: None Conflict of Interest: None

Citation: Gautam N, Ojha R, Kharel S, Gajurel BP, Sitaula S, Karn R, Rajbhandari R, Shrestha A. Clinical Manifestations, Neuroimaging Findings, and Treatment of Idiopathic Intracranial Hypertension in a Nepalese Tertiary Centre. NMJ 2012;4(2):468-72. DOI10.3126/nmj.v4i2.40038 


\section{INTRODUCTION}

Idiopathic Intracranial Hypertension(IIH), also called pseudotumor cerebri or benign intracranial hypertension is a newonset headache or worsening of preexisting headache along with various clinical features and signs of raised Intracranial Pressure (ICP). ${ }^{1}$ The diagnosis is commonly made using modified Dandy criteria and is a diagnosis of exclusion. The combination of raised ICP without hydrocephalus or mass lesion, maybe papilloedema but a normal Cerebrospinal Fluid(CSF) profile with no underlying etiology helps in the diagnosis of IIH. ${ }^{2}$

A meta-analysis showed the annual incidence of IIH was 1.20 per 100000 ranging from 0.03 to 2.36 per 100000 . There was female predominance $(87 \%)$ with a mean age of 29.8 years. ${ }^{3} \mathrm{IIH}$ is a disorder mainly affecting young and obese females of mainly reproductive age(20-40 years). It has shown a strong association with obesity. ${ }^{4}$ Headache, transient visual obscuration, diplopia, and pulsatile tinnitus are the common clinical features and visual and oculomotor systems are abnormal in the neurological examination. ${ }^{5}$ The clinical features of IIH in Asians are similar to Caucasians but the significant differences lie in the bodyweight/ obesity. However, there is ethnic variation reported in the pathogenesis of IIH. $^{6}$

Only a few studies on clinico-demographic and outcomes of IIH are conducted in the Asian population, mainly Chinese, Japanese, and Indian patients. A recent study done by $\mathrm{Pal}$ et al. in India described the clinical and demographic profile, clinical features, and outcomes of IIH among 33 patients ( 31 female and 2 male). The patients of the Indian subcontinent were found to have a good response to medical management. ${ }^{7}$ However, there are no clinical studies of IIH reported from Nepal. Therefore, we conducted a retrospective study to evaluate the clinico-demographic characteristics, clinical features, neuroimaging characteristics, and outcomes of IIH patients.

\section{MATERIALS AND METHODS}

This is the retrospective study done in patients with IIH admitted to the Neurology department of Tribhuvan University Teaching Hospital from 2019 June to 2021 May and presented to the Neuro-ophthalmology outpatient clinic of the hospital for followup. The study was approved by the institutional review committee of the Institute of Medicine. Patients who fulfill the diagnostic criteria of IIH (2013), admitted to the Neurology department for cerebrospinal fluid (CSF) opening pressure measurement and came to follow-up in Neuro-ophthalmology outpatient clinic at least 2 times were included in the study: defined as a probable or definite diagnosis. ${ }^{2}$ Patients were excluded if record section data had incomplete details of patients. Details of patient's demographic features, vitals, clinical symptoms and signs, neurological examination findings, laboratory investigations, ophthalmological evaluation details, CSF examination along with opening pressure, MRI and MRV brain, and treatment details were recorded.

In demographic data, the Body mass index(BMI) of all the patients was calculated. The patient's education level was categorized as primary, secondary, and college level. The patient's occupation was also classified and the current address was recorded as
Kathmandu or outside Kathmandu. History of drugs, head injury, migraine, weight gain, and comorbidity of hypothyroidism was recorded. If a headache was present, its characteristics were specified along with associated symptoms. Involvement of various cranial nerves and their findings such as papilledema, visual acuity, visual fields were recorded. CSF opening pressure was measured with a spinal manometer in $\mathrm{cm}$ of $\mathrm{H}_{2} 0$. All the patients underwent magnetic resonance imaging (MRI) and venogram (MRV) ruling out cerebral venous thrombosis and MRI findings were recorded.

We used SPSS software for Mac, Version 25 (SPSS Inc., USA) to store and analyze the data. Mean, frequency, standard deviation, range, and percentage of various variables were calculated. Results were reported as mean \pm standard deviation, frequency, and percentage.

\section{RESULTS}

A total of 16 patients were included in our study, out of which $12(75 \%)$ were female and $4(25 \%)$ were male (Table 1$)$. The mean age of patients was $33.5 \pm 10.3$ years, ranging from 20 to 48 years. Mean BMI was $25.9 \pm 1.5 \mathrm{~kg} / \mathrm{m}^{2}$ ranged from 23.8 to $28.3 \mathrm{~kg} / \mathrm{m}^{2}$. BMI of 10 patients $(62 \%)$ were more than 25 , and $6(38 \%)$ were below 25. Most of our patients were college graduates $(43 \%)$, followed by education of secondary (38\%) and primary level (19\%). Housewives were the most common among our patients $(38 \%)$, followed by students $(25 \%)$, others $(25 \%)$, and unemployed (12.5\%). The majority of patients were from outside Kathmandu (62\%) and 38\% were from Kathmandu. In drug history, 1 patient was taking Lithium for about 4 years, and 2 female patients were under oral contraceptive pills. Migraine was present in 5 patients, 1 with aura and 4 without aura. One patient had a head injury in the past, however, no intracranial lesion was seen in neuroimaging then. Two patients had a recent weight gain of about $4 \mathrm{kgs}$ in the last 3 months. Blood pressure in patients' data showed mean systolic of $119.4 \pm 11.8$ and diastolic $79.7 \pm 10.1$, out of which 4 patients were hypertensive.

Table 1: Demography of patients with idiopathic intracranial hypertension

\begin{tabular}{ll}
\hline Characteristics & Mean/Frequency/Percentage $(\mathbf{n}=\mathbf{1 6})$ \\
\hline Mean Age: & $33.5 \pm 10.3$ years (range: $20-48$ years) \\
\hline Male: Female & $4: 12$ \\
\hline Mean BMI (kg/m2) & $25.9 \pm 1.5$ range $(23.8-28.3)$ \\
\hline Education & \\
$\quad$ Primary & $3(19 \%)$ \\
$\quad$ Secondary & $6(38 \%)$ \\
$\quad$ College & $7(43 \%)$ \\
\hline Occupation & \\
$\quad$ Student & \\
$\quad$ Housewife & $4(25 \%)$ \\
$\quad$ Unemployed & $6(38 \%)$ \\
$\quad$ Others & $2(12.5 \%)$ \\
\hline Address & $4(25 \%)$ \\
$\quad$ Kathmandu & \\
Outside Kathmandu & $6(38 \%)$ \\
& $10(62 \%)$ \\
\hline
\end{tabular}




\begin{tabular}{|ll}
\hline Characteristics & Mean/Frequency/Percentage (n=16) \\
\hline $\begin{array}{l}\text { Drug History } \\
\text { Lithium }\end{array}$ & $1(6.2 \%)$ \\
$\quad$ Oral contraceptive pill & $2(12.5 \%)$ \\
\hline $\begin{array}{l}\text { History of Migraine } \\
\quad \text { Migraine with Aura }\end{array}$ & $1(6.2 \%)$ \\
$\quad$ Migraine without Aura & $4(25 \%)$ \\
\hline Head Injury & $1(6.2 \%)$ \\
\hline History of Weight Gain & $2(12.5 \%$ \\
\hline $\begin{array}{l}\text { Blood Pressure (mmHg) } \\
\text { Mean systolic }\end{array}$ & $119.4 \pm 11.8$ \\
$\quad$ Mean Diastolic & $79.7 \pm 10.1$ \\
\hline Hypothyroidism & $2(12.5 \%)$ \\
\hline
\end{tabular}

BMI: Body Mass Index

Out of $16 \mathrm{IIH}$ patients, $12(75 \%)$ patients had either headache or ocular pain (Table 2). Headache was a persistent heaviness in 9 patients and early morning heaviness was found in 3 patients. Three patients also complained of a burning type of pain in the head and 3 had a pulsating headache. However, most patients' headache severity was mild(31\%) to moderate(31\%), and only one patient complained of severe headache. Four patients had transient visual symptoms whereas 3 patients had persistent visual impairment. One of our patients had very rapid worsening of bilateral visual symptoms to perceiving hand movements. Two patients had nausea during headache and 1 complained of scalp tenderness. Tinnitus was reported by 3 patients and photophobia was also seen in 3 .

Table 2 Characteristics of Headache and its associated symptoms in Idiopathic Intracranial hypertension

\begin{tabular}{ll}
\hline Characteristics & Frequency/Percentage (n=16) \\
\hline Burning type & $3(19 \%)$ \\
\hline $\begin{array}{l}\text { Heaviness } \\
\text { Morning only } \\
\quad \text { Any time of the day }\end{array}$ & $3(19 \%)$ \\
\hline Pulsating & $9(56 \%)$ \\
\hline Daily continuous & $3(19 \%)$ \\
\hline Ocular Pain & $3(19 \%)$ \\
\hline $\begin{array}{l}\text { Severity } \\
\quad \text { Mild } \\
\quad \text { Moderate }\end{array}$ & $5(31 \%)$ \\
\hline Severe & $5(31 \%)$ \\
\hline Visual Symptoms & $5(31 \%)$ \\
$\quad$ Transient & $1(6.2 \%)$ \\
\hline Persistent & $4(25 \%)$ \\
Nausea & $3(19 \%)$ \\
\hline Scalp Tenderness & $2(12.5 \%)$ \\
\hline Tinnitus & $1(6.2 \%)$ \\
\hline Photophobia & $3(19 \%)$ \\
\hline
\end{tabular}

Reduced visual acuity and progressive visual loss were found in $44 \%$ of IIH patients (Table 3 ). Double vision was noted in 2 patients and both were found to involve unilateral lateral rectus muscle palsy. In papilledema grading, grades 2 and 4 were found in $37.5 \%$ of patients each and $25 \%$ had grade 3 . Normal CSF opening pressure was found in $19 \%, 44 \%$ had CSF opening pressure at a range of $20-30 \mathrm{~cm} \mathrm{H}_{2} \mathrm{O}$ and more than $30 \mathrm{~cm} \mathrm{H}_{2} \mathrm{O}$ in $37.5 \%$. Maximum CSF opening pressure was reported to be $38 \mathrm{~cm} \mathrm{H}_{2} 0$. Fifteen IIH patients $(93.7 \%)$ were subtyped as Typical IIH and 1 patient was diagnosed as Fulminant IIH. Three patients(19\%) fitted for a probable diagnosis of IIH due to normal CSF opening pressure, the rest 13 patients were categorized as definite IIH. The patient with fulminant IIH was a young female with rapidly progressive visual loss and needed ventriculoperitoneal (VP) shunting. Headache or ocular pain is mild to moderate in most patients. So, acetaminophen was used in most patients (44\%), followed by NSAIDs (25\%) used naproxen or ibuprofen and acetaminophen combination and codeine with acetaminophen combination in $6.2 \%$. The frequency to use these pain abortive medications was occasional in $44 \%$, less than 3 times a week in $19 \%$, and more than 3 times a week in $12.5 \%$. Acetazolamide was used for treatment in 15 patients. 14 patients had good compliance to medication and 2 patients had occasional missed doses. Acetazolamide was safe and tolerable to our patients. Only 3 patients reported mild adverse effects: 1 had reduced appetite and 2 complaints of tingling sensation in bilateral hands. Along with acetazolamide, 3 patients have been prescribed amitriptyline and 2 patients with dosulepin.

Table 3 Cranial Nerve findings in Idiopathic Intracranial hypertension

\begin{tabular}{ll}
\hline Characteristics & Mean/Frequency (n=16) \\
\hline Progressive Visual Loss & $7(44 \%)$ \\
\hline Double Vision & $2(12.5 \%)$ \\
\hline Lateral Rectus Palsy & $2(12.5 \%)$ \\
\hline Papilledema Grading & \\
$\quad$ Grade 2 & $6(37.5 \%)$ \\
$\quad$ Grade 3 & $4(25 \%)$ \\
$\quad$ Grade 4 & $6(37.5 \%)$ \\
\hline Mean Opening CSF pressure (cm H20) & $26.8 \pm 8.2$ \\
Normal Opening CSF pressure & $3(19 \%)$ \\
CSF pressure 20-30 cm H20 & $7(44 \%)$ \\
CSF pressure $>$ 30 cm H20 & $6(37.5 \%)$ \\
Maximum CSF pressure & $38 \mathrm{~cm} \mathrm{H20}$ \\
\hline Subtype & \\
$\quad$ Typical IIH & $15(93.7 \%)$ \\
$\quad$ Fulminant IIH & $1(6.2 \%)$ \\
\hline Diagnosis & \\
$\quad$ Probable & $3(19 \%)$ \\
$\quad$ Definite & $13(81.2 \%)$ \\
\hline Abortive Treatment & \\
Acetaminophen & \\
$\quad$ NSAIDs & \\
Codeine plus acetaminophen & $1(44 \%)$ \\
Frequency of abortive treatment & $4(25 \%)$ \\
Occasional & \\
< 3 times a week & \\
> 3 times a week & $7(44 \%)$ \\
\hline
\end{tabular}

CSF: Cerebrospinal fluid; NSAIDs: Non-steroid antiinflammatory drugs

All patients underwent MRI and MRV brain and cerebral venous thrombosis along with other intracranial etiology were ruled out. $56 \%$ of IIH patients had normal neuroimaging scans. Seven patients (44\%) patients had some abnormal findings: partial empty sella being the most common (44\%). (Table 4) 
Table 4: Magnetic Resonance Imaging findings

\begin{tabular}{ll}
\hline MRI Findings & Frequency (percentage) \\
\hline Normal Scan & $9(56 \%)$ \\
\hline Abnormal findings & $7(44 \%)$ \\
\hline Partial empty sella & $7(44 \%)$ \\
\hline Tortuosity of Optic Nerve & $5(31 \%)$ \\
\hline Flattened posterior eyeball & $5(31 \%)$ \\
\hline Hypoplastic transverse sinus & $3(19 \%)$ \\
\hline
\end{tabular}

MRI: Magnetic Resonance Imaging

\section{DISCUSSION}

This study has included the details of clinical manifestation, investigational findings, and treatment modalities of IIH in a hospital-based setting. IIH is an uncommon diagnosis, usually missed by physicians and general neurologists in outpatient settings. Mostly, IIH is misdiagnosed as tension-type headache, migraine without aura, or headache of ocular or paranasal sinus etiology, and patients have a history of visiting doctors of various specialties.

The annual incidence of IIH is about 1.20 per 100000 population. Various hospital-based studies of duration 1-7 years included 14 patients in Kim et al, 33 in Pal et al, 68 in Sina et al, 81 in Radhakrishnan et al, 139 in Al-hashel et al, and 50 in Giuseffi et al. ${ }^{4,5,7-10}$ Although our study is a 2-year study, only a smaller number of patients could be included. Due to mild to moderate headache episodes and mild vision impairment in most patients with slow progression, IIH patients may not frequently visit the hospital. Further, the diagnosis of IIH needs specialization expertise and correlation of clinical symptoms, neuroimaging, and CSF findings. This might have caused a larger number of IIH patients to remain unrecognized in low and middle economic countries.

The exact mechanism of association of BMI and IIH is not clear yet. However, most of the previous studies have shown the positive relation of IIH with higher BMI and weight gain., ${ }^{50-12}$ Majority of our patients had BMI $>25$, however, none had BMI $>30$. Our results were similar to Kim et al, in contrast to western studies where the obesity percentage in IIH was higher. ${ }^{6,12,13}$ Only 2 patients gave a history of weight gain. Daniels et al have reported even in non-obese moderate weight gain is the risk factor for IIH and higher weight gain and BMI are further linked with increased risk of IIH. ${ }^{11}$ Similar to previous studies, female predominance was found in our IIH patients. ${ }^{10,14}$ Despite similar risk factors and age-group, female preponderance was found among IIH patients in the study of Bruce et al. ${ }^{15}$ Hormonal etiology could be a predisposing factor for IIH in the female during the fertility period. Previous studies had shown an association of OCP and $\mathrm{IIH}$ which was not found to be related in a recent study by Kilgore et al. ${ }^{16}$

Headache characteristics in IIH are nonspecific. Usually early symptoms are similar to tension-type headaches or migraine. Papilledema, visual loss, and ocular pain along with daily mild to moderate headache are usually the characteristic findings of IIH. ${ }^{5}$ Pulsating headache with nausea and vomiting could be misdiagnosed as a migraine attack. Since the prevalence of migraine is more common, diagnosis of IIH in a known case of migraine is difficult. Tinnitus is another typical finding of IIH; however, it was just reported in our 3 patients. ${ }^{10}$ Transient visual symptoms are important findings of $\mathrm{IIH}$, and progressive visual loss needs to be prompt evaluation and treatment. ${ }^{17}$ Cranial nerve involvement is not frequent, but like ours, involvement of the abducent nerve has been found in most studies. ${ }^{10}$ High CSF opening pressure is an important diagnostic criterion and frequently correlates with the severity of IIH, especially visual symptoms. ${ }^{7}$ Few of our patients were probable IIH with normal CSF opening pressure. However, the presence of visual loss, papilledema, enlarged blind spot, and ruling out other etiologies in our patients were suggestive of $\mathrm{IIH} .{ }^{18}$ Digre et al found unimproved headache with antimigraine therapy should also be evaluated for IIH even if papilledema was absent. ${ }^{19}$

MRI findings may not be prominent in IIH, subtle signs such as flattening of the posterior eyeball, tortuous optic nerve, prominent CSF around the optic nerve, and partially empty sella can be observed..$^{20}$ However, MRI helps to rule out other secondary conditions including CVT. Behcet's disease is commonly associated with sinus venous thrombosis in Mediterranean lands, may present with raised ICP and neurological involvement. Similarly, Tuberculoma and neurocysticercosis should be ruled out in South-Asian and South-America countries. ${ }^{4}$ Some studies have reported transverse sinus stenosis in IIH which may need special 3D PC MRV technique. ${ }^{21}$

Medical treatment with acetazolamide is the common management method that helps to gradually reduce the ICP and improves visual findings and disc edema. Acetazolamide was usually safe and tolerable in our patients, likely use of lower dose in them. However, frequent adverse effects of severe fatigue, nausea, diarrhea, and paresthesia of limbs can be seen in some patients in higher doses. ${ }^{20}$

Some other drugs such as topiramate and furosemide have also had some benefits in IIH. Non-pharmacological treatment such as weight loss methods could also be beneficial for some patients. All of our patients improved well with oral medication, except 1 improved only after VP shunting. Surgical or interventive methods are single or serial lumbar puncture, optic nerve sheath fenestration, CSF diversion surgery such as lumbo-peritoneal shunting, VP shunting, or transverse sinus shunting had also shown beneficial in IIH management. Besides VP shunting, there are studies of venous sinus stenting with good clinical outcomes..$^{10,22}$

Limitations of this study are being retrospective type, details of other likely risk factors such as Vitamin A, endocrine disorders, and sleep disorders were not well documented. Although this is a 2-years study from a tertiary hospital, only a smaller number of patients could be recruited.

\section{CONCLUSIONS}

IIH is an uncommon diagnosis but should be suspected in patients with chronic headaches with visual impairment. Papilledema is a common sign in IIH and blind spot enlargement with reduced visual acuity can be other important findings. IIH responds well to oral medication and rarely needs surgical intervention. In low-resource settings, proper history along with neurological and ophthalmological examinations can even detect the early features and timely referral can save the vision and disability of IIH patients. 


\section{Acknowledgments}

We would like to thank the staff from the record section of Tribhuvan University Teaching Hospital along with staff from the Neuroophthalmology unit, BP Koirala lions center for ophthalmic studies for their support.

\section{REFERENCES}

1. Headache Classification Committee of the International Headache Society (IHS) The International Classification of Headache Disorders, 3rd edition. Cephalalgia. 2018;38:1-211. Crossref

2. Friedman DI, Liu GT, Digre KB. Revised diagnostic criteria for the pseudotumor cerebri syndrome in adults and children. Neurology. 2013;81(13):1159-65. Crossref

3. McCluskey G, Doherty-Allan R, McCarron P, Loftus AM, McCarron LV, Mulholland D, et al. Meta-analysis and systematic review of population-based epidemiological studies in idiopathic intracranial hypertension. Eur J Neurol. 2018;25(10):1218-27. Crossref

4. Radhakrishnan K, Thacker AK, Bohlaga NH, Maloo JC, Gerryo SE. Epidemiology of idiopathic intracranial hypertension: a prospective and case-control study. J Neurol Sci. 1993;116(1):18-28. Crossref

5. Giuseffi V, Wall M, Siegel PZ, Rojas PB. Symptoms and disease associations in idiopathic intracranial hypertension (pseudotumor cerebri): a case-control study. Neurology. 1991;41(2 ( Pt 1)):23944. Crossref

6. Kim TW, Choung HK, Khwarg SI, Hwang J-M, Yang HJ. Obesity may not be a risk factor for idiopathic intracranial hypertension in Asians. Eur J Neurol. 2008;15(8):876-9. Crossref

7. Pal A, Sengupta P, Biswas D, Sen C, Mukherjee A, Pal S. Pattern of Idiopathic Intracranial Hypertension in Indian Population. Ann Indian Acad Neurol. 2019;22(1):47-51. Crossref

8. Kim TW, Choung HK, Khwarg SI, Hwang JM, Yang HJ. Obesity may not be a risk factor for idiopathic intracranial hypertension in Asians. European journal of neurology. 2008;15(8):876-9. Website

9. Sina F, Razmeh S, Habibzadeh N, Zavari A, Nabovvati M. Migraine headache in patients with idiopathic intracranial hypertension. Neurol Int. 2017;9(3):7280. Crossref

10. Al-Hashel JY, Ismail II, Ibrahim M, John JK, Husain F, Kamel WA, et al. Demographics, Clinical Characteristics, and Management of Idiopathic Intracranial Hypertension in Kuwait: A Single-Center Experience. Frontiers in Neurology. 2020;11:672. Crossref

11. Daniels AB, Liu GT, Volpe NJ, Galetta SL, Moster ML, Newman NJ, et al. Profiles of obesity, weight gain, and quality of life in idiopathic intracranial hypertension (pseudotumor cerebri). American journal of ophthalmology. 2007;143(4):635-41. Crossref
12. Brahma VL, Snow J, Tam V, Ross AG, Tamhankar MA, Shindler $\mathrm{KS}$, et al. Socioeconomic and Geographic Disparities in Idiopathic Intracranial Hypertension. Neurology. 2021;96(23):e2854-60. Website

13. Hermes SM, Miller NR, Waslo CS, Benes SC, Tanne E. Mortality among patients with idiopathic intracranial hypertension enrolled in the IH Registry. Neurology. 2020;95(7):e921-9. Crossref

14. Miah L, Strafford H, Fonferko-Shadrach B, Hollinghurst J, Sawhney IM, Hadjikoutis S, Rees MI, Powell R, Lacey A, Pickrell WO. Incidence, Prevalence, and Health Care Outcomes in Idiopathic Intracranial Hypertension: A Population Study. Neurology. 2021;96(8):e1251-61. Crossref

15. Bruce BB, Kedar S, Van Stavern GP, Monaghan D, Acierno MD, Braswell RA, et al. Idiopathic intracranial hypertension in men. Neurology. 2009;72(4):304-9. $\underline{\text { Crossref }}$

16. Kilgore KP, Lee MS, Leavitt JA, Frank RD, McClelland CM, Chen JJ. A population-based, case-control evaluation of the association between hormonal contraceptives and idiopathic intracranial hypertension. Am J Ophthalmol. 2019;197:74-9. Crossref

17. Thambisetty M, Lavin PJ, Newman NJ, Biousse V. Fulminant idiopathic intracranial hypertension. Neurology. 2007;68(3):22932. $\underline{\text { Crossref }}$

18. Suh SY, Kim SJ. IIH with normal CSF pressures? Indian J Ophthalmol. 2013;61(11):681. Crossref

19. Digre KB, Nakamoto BK, Warner JE, Langeberg WJ, Baggaley SK, Katz BJ. A comparison of idiopathic intracranial hypertension with and without papilledema. Headache. 2009;49(2):185-93. Crossref

20. Mollan SP, Ali F, Hassan-Smith G, Botfield H, Friedman DI, Sinclair AJ. Evolving evidence in adult idiopathic intracranial hypertension: pathophysiology and management. J Neurol Neurosurg Psychiatry. 2016;87(9):982-92. Crossref

21. Fera F, Bono F, Messina D, Gallo O, Lanza PL, Auteri W, Nicoletti G, Santoro G, Quattrone A. Comparison of different MR venography techniques for detecting transverse sinus stenosis in idiopathic intracranial hypertension. J Neurol. 2005;252(9):1021-5. Crossref

22. Levitt MR, Albuquerque FC, Gross BA, Moon K, Jadhav AP, Ducruet AF, Crowley RW. Venous sinus stenting in patients without idiopathic intracranial hypertension. J Neurointerv Surg. 2017;9(5):512-5. Crossref 